\title{
Consumption of antidiabetic medicines in Portugal: results of a temporal data analysis of a thirteen-year study (2005-2017)
}

\author{
Artur Mendes Moura $^{*^{*} \text { (D), Sofia Oliveira Martins }}{ }^{1}$ (D) and João Filipe Raposo ${ }^{2,3}$ (D)
}

\begin{abstract}
Background: Studies of drug utilization in patients with diabetes, a chronic disease that can be treated with a wide range of available medicines, have attracted substantial social and clinical interest.

Objective: To characterize antidiabetic medicine consumption between 2005 and 2017, to evaluate the trends of these medicines in mainland Portugal, and to compare district consumption. An additional objective was to perform a statistical analysis on drug consumption in different regions of Portugal.

Methods: A descriptive, longitudinal observational study; the setting was mainland Portugal ( excluding Azores and Madeira).

Each medicine has a respective defined daily dose (DDD). The sum of the DDD, provides the annual consumption in terms of the DDD for each district each year. When calculating the annual average for the resident district population and the number of days in a year, the denominator is expressed as 1000 inhabitants per day (TID). Main outcome measure: The DDD/TID for mainland Portugal (for all districts) between 2005 and 2017 for antidiabetic medicines.

Information was obtained from the official database of prescription medicine invoices with reimbursement in mainland Portugal.
\end{abstract}

Results: In mainland Portugal, the antidiabetic medicine consumption was 49.3 DDD/TID in 2005 and 88.2 DDD/ TID in 2017. The consumption of insulins and their analogs increased from 10.8\% to $17.4 \%$ compared to the total consumption of antidiabetic medicines.

In 2017, the level of biguanide consumption was 23.1 DDD/TID, that of sulphonylurea consumption was 15.8 DDD/

TID, that of DPP-4 inhibitor consumption was 6.8 DDD/TID, and that of SGLT2 inhibitor consumption was $3.0 \mathrm{DDD} /$

TID. The oral consumption of fixed-dose combinations reached 21.4 DDD/TID.

After employing a geographical division between north and south and between coastal and inland regions, the consumption of several different drugs showed statistically significant differences.

(Continued on next page)

\footnotetext{
* Correspondence: arturmoura@ff.ulisboa.pt

${ }^{1}$ Faculty of Pharmacy, University of Lisbon, Avenida Professor Gama Pinto, 1649-003 Lisboa, Portugal

Full list of author information is available at the end of the article
}

(c) The Author(s). 2021 Open Access This article is licensed under a Creative Commons Attribution 4.0 International License, which permits use, sharing, adaptation, distribution and reproduction in any medium or format, as long as you give appropriate credit to the original author(s) and the source, provide a link to the Creative Commons licence, and indicate if changes were made. The images or other third party material in this article are included in the article's Creative Commons licence, unless indicated otherwise in a credit line to the material. If material is not included in the article's Creative Commons licence and your intended use is not permitted by statutory regulation or exceeds the permitted use, you will need to obtain permission directly from the copyright holder. To view a copy of this licence, visit http://creativecommons.org/licenses/by/4.0/ The Creative Commons Public Domain Dedication waiver (http://creativecommons.org/publicdomain/zero/1.0/) applies to the data made available in this article, unless otherwise stated in a credit line to the data. 


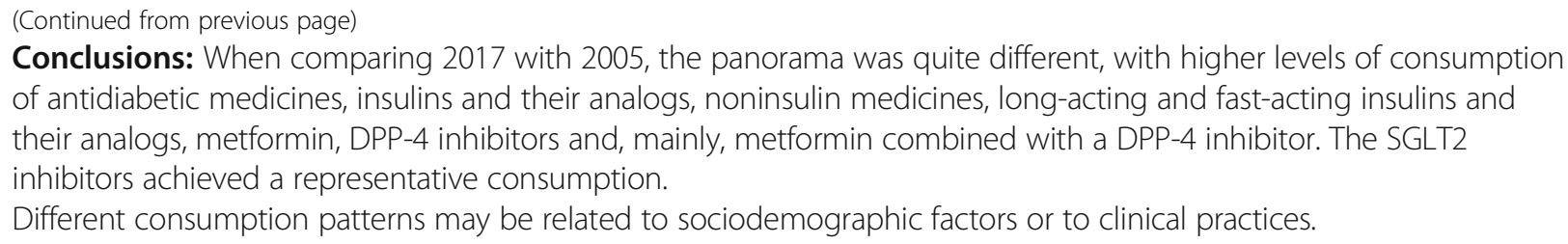

Keywords: Diabetes Mellitus, Insulin, Hypoglycemic agents, Drug utilization, Portugal

\section{Background}

In 1977, the World Health Organization (WHO) defined the concept of drug utilization as the marketing, distribution, prescription, and use of drugs in a society [1]. Drug utilization has medical, social, and economic consequences. In 2003, the WHO published guidelines on drug utilization research, and in addition to their usefulness, highlighted the importance of these studies [2].

Numerous drug utilization studies examining the methodological aspects have been published [3-9]. In this context and as diabetes is a chronic disease, diabetes is appropriate for the application of this type of study. However, few studies have been published in this field.

The high level of prevalence is verified based on the information released by the Organization for Economic Cooperation and Development (OECD) that highlights an age-standardized diabetes prevalence of $6.0 \%$ for the population aged 18-99 years old in 28 European countries and $9.9 \%$ for Portugal using data collected in 2017 [10]. The Portuguese National Diabetes Observatory $(O N D)$ report showed a prevalence of diabetes of $13.3 \%$ for 2015 in the 20-79-year-old population, which includes an estimated prevalence of $5.8 \%$ for undiagnosed individuals in the same population [11]. We should bear in mind that diabetes prevalence data includes diabetes mellitus type 1 and 2, with diabetes mellitus 1 representing $5-10 \%$ of existing cases and diabetes mellitus type 2 accounting for $90-95 \%$ [12].

The recommendations for the treatment of type 1 diabetes mellitus in Portugal propose different insulin therapeutic regimens [13], which incorporate the scientific evidence available for insulin therapy. The recommendations for the treatment of type 2 diabetes mellitus propose different therapeutic regimens. In Portugal, the main documents on this matter are the recommendations of the Portuguese Society of Diabetology (SPD) [14-16] and the Clinical Guidelines of the Portuguese General Directorate of Health (DGS) [17-19], which incorporate the scientific evidence available for a wide range of antidiabetic drugs. The general approach to treat a patient with type 2 diabetes mellitus is the following: metformin is the first-line treatment; when a patient is not adequately controlled with metformin, a second noninsulin medication may be added; this second medication may be a sulphonylurea, a dipeptidyl peptidase-4 (DPP-4) inhibitor or a glitazone and, in the more recent guidelines, a glucagon-like peptide-1 (GLP1) analog or a sodium-glucose cotransporter 2 (SGLT2) inhibitor. If even with this combined medication, the patient is not glycemic controlled, it is possible to add a third antidiabetic drug from other classes of noninsulin drugs. However, in every stage, if the patient presents a high level of glycated hemoglobin (>10\%) $[17,19]$, therapy with insulin should be started.

Insulin is the only treatment available for type 1 diabetes mellitus, but due to the low prevalence of this disease, we can consider that consumption fluctuations for this drug are essentially related to type 2 diabetes mellitus. The consumption of noninsulin medicines is related to the treatment of type 2 diabetes mellitus.

Drug utilization studies in diabetes concerning the consumption of antidiabetic medicines often do not differentiate between the types of diabetes. Drug utilization studies on the consumption of medicines are usually expressed as prevalence, or exposition, of those drugs in a population. It can be the population of a country (e.g., Denmark [20]) or a region or other specific area (e.g., Granada metropolitan area of Andalusia region, Spain [21]).

In addition to analyzing the consumption of antidiabetic drugs, these studies provide insights into the effects of successive therapeutic guidelines and the introduction of new therapeutic classes of antidiabetic drugs into the market in clinical practice. The results can also provide valuable information for the rational use of medicines and allow decision-making regarding the policy for medicines.

The aim of this study was to characterize antidiabetic medicine consumption between 2005 and 2017, to evaluate the trends of these medicines in mainland Portugal, and to compare district consumption. An additional objective was to perform statistical analysis of the consumption of these drugs in different regions of Portugal.

\section{Methods}

This study was observational, descriptive, and longitudinal; the setting was mainland Portugal (excluding Azores and Madeira). 
All medicines, including antidiabetic medicines, were categorized according to the fifth level code of the Anatomical Therapeutic Chemical Classification System (ATC). For each ATC, there is a respective defined daily dose (DDD). All DDD units were reported in accordance with the ATC/DDD guidelines for implementation in 2018 [22]. Knowing the total units of DDD of a medicine for each year and each district, we obtained the consumption of that medicine for all 18 Portuguese districts from 2005 to 2017.

If the DDD units were for a specific district and a respective year, it was necessary to divide the DDD units by the annual average resident population in that district [23] and by the number of days depending on the specific year, considering the leap years. To express the DDD per thousand inhabitants per day (TID), it is necessary to multiply this value by 1000 .

Consequently, it is possible to calculate the DDD/TID of mainland Portugal for a specific medicine using the total DDD consumption in all districts and the total resident population using the data of all districts.

From the fifth to the fourth second level of the ATC code, the DDD/TID ratios were calculated consecutively from sum totals of the respective DDD values for the group of drugs belonging to the fourth level of the ATC code for the district population and respective year. The same procedure was applied to each group of drugs for the third ATC level, in accordance with their categorization in the group of insulins and their analogs or to the group of noninsulin antidiabetic drugs. Finally, for the second ATC level, the DDD/TID was calculated for antidiabetic drugs.

The main outcome measure was the DDD/TID for mainland Portugal (including for all districts), between 2005 and 2017, for antidiabetic medicines, for insulins and analogs (including the different types of insulins), and for noninsulin medicines (including the different types of noninsulin medicines).

The average levels of consumption of antidiabetic drugs, insulins and their analogs, and noninsulin antidiabetic drugs were calculated using the method described below to compare geographical areas that were larger than districts. All the districts were grouped into two categories (see Fig. 1) to identify the group of districts from the north and south, in addition to the group of districts from the coastal and inland regions. The north group included the districts most representative of the North and Central Health Regions, and the south group included the districts most representative of the Lisbon and Tagus Valley, Alentejo and Algarve Health Regions.

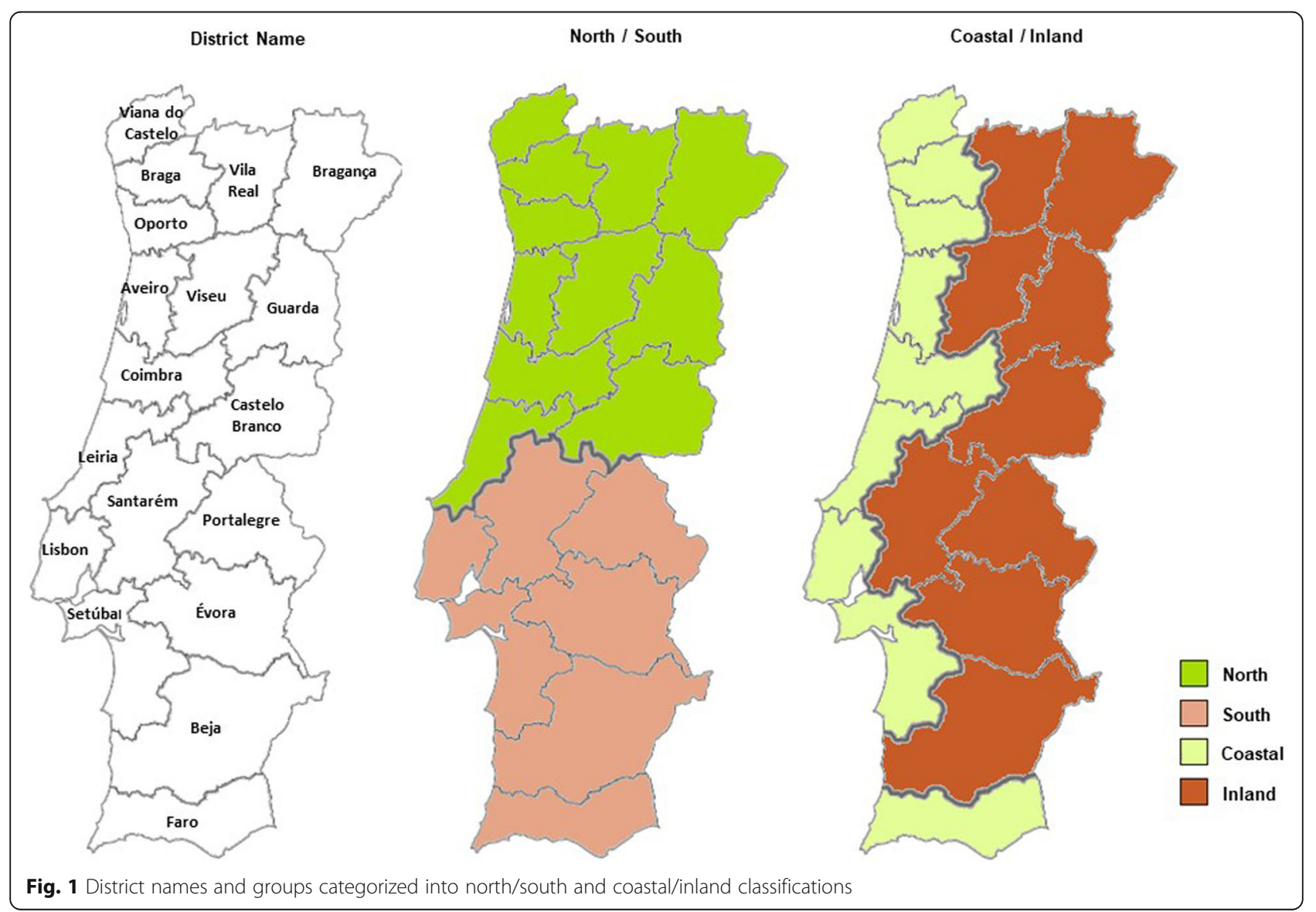


Therefore, two groups that jointly, contained all the districts of mainland Portugal were obtained. The coastal group included the districts along the Atlantic strip, except for the Beja district, as it is essentially inland; all the remaining districts, including the Beja district, were included in the inland group.

The database used for this study was provided by Infarmed (Portuguese Medicines Authority). The database was created as a result of the reconciliation of invoices sent by community pharmacies to the Health Service's Central Management (ACSS) for subsidized drugs in mainland Portugal. All antidiabetic drugs in Portugal are subsidized by the National Health Service irrespective of their income as long as they are either Portuguese or residing in Portugal. Patients obtain medication at community pharmacies by presenting a physician prescription. Community pharmacies are spread all over mainland Portugal, covering all districts, therefore allowing patients easy access to antidiabetic medicines. ACSS is not responsible for the invoice reconciliation for the Azores and Madeira regions; therefore, the database only has data for mainland Portugal.

The database contained the total DDD units for each antidiabetic medicine, according to the fifth level code of the ATC for the respective district (18 districts) and the respective year (between 2005 and 2017). For the oral fixed-dose combination drugs, the database did not include the annual DDD units. Instead, it contained the number of tablets consumed, for each of these medicines, per district and year. This information allowed the calculation of the annual DDD units for each oral fixeddose combination drug.

The arithmetic calculations were performed using Microsoft Office Excel 2007 software and the statistical calculations, including the Mann-Whitney $U$ test, were performed using SPSS ( $v 25$ ) software. The level of statistical significance was set to $p<0.05$, with a $95 \%$ confidence interval $(\mathrm{CI})$.

\section{Results}

Table 1 presents the consumption of antidiabetic drugs, insulins and their analogs, and noninsulin antidiabetic drugs, including all types of these medicines, reported in DDD/TID from 2005 to 2017.

The consumption of antidiabetic drugs increased from 49.3 DDD/TID in 2005 to 88.2 DDD/TID in 2017, indicating an annual average growth rate of $6.6 \%$.

Insulins and their analogs, with a consumption of 5.3 DDD/TID in 2005 and 15.4 DDD/TID in 2017 exhibited an annual average growth rate that was greater than the increase in the consumption of antidiabetic drugs.

Table 1 The consumption of antidiabetic drugs in DDD/TID, from the second ATC level to the fourth ATC level, between 2005 and 2017

\begin{tabular}{|c|c|c|c|c|c|c|c|c|c|c|c|c|c|c|}
\hline \multirow[t]{2}{*}{ ATC } & \multirow[t]{2}{*}{ Medicines } & 2005 & 2006 & 2007 & 2008 & 2009 & 2010 & 2011 & 2012 & 2013 & 2014 & 2015 & 2016 & 2017 \\
\hline & & \multicolumn{13}{|c|}{ DDD/TID } \\
\hline $\mathrm{A} 10$ & Antidiabetics & 49.3 & 52.3 & 55.4 & 60.8 & 64.6 & 67.8 & 70.2 & 73.6 & 78.9 & 82.2 & 84.4 & 86.0 & 88.2 \\
\hline A10A & Insulins and analogues & 5.3 & 6.9 & 7.7 & 8.6 & 9.2 & 10.1 & 10.9 & 11.8 & 13.1 & 13.9 & 14.4 & 15.0 & 15.4 \\
\hline$A 10 B$ & Non-insulin antidiabetics & 44.0 & 45.4 & 47.7 & 52.2 & 55.4 & 57.7 & 59.3 & 61.7 & 65.8 & 68.3 & 69.9 & 71.0 & 72.9 \\
\hline $\mathrm{A} 10 \mathrm{~A}$ & Insulins and analogues & & & & & & & & & & & & & \\
\hline$A 10 A B$ & Fast-acting insulins & 1.0 & 0.9 & 1.2 & 1.6 & 1.9 & 2.2 & 2.6 & 3.0 & 3.4 & 3.7 & 3.9 & 4.1 & 4.3 \\
\hline A10AC & Intermediate-acting insulins & 3.0 & 3.1 & 3.5 & 3.5 & 3.1 & 3.0 & 2.7 & 2.5 & 2.4 & 2.4 & 2.3 & 2.1 & 2.0 \\
\hline$A 10 A D$ & Combined-acting insulins & 1.4 & 2.9 & 3.0 & 3.0 & 3.0 & 3.0 & 3.0 & 3.0 & 3.1 & 3.1 & 2.9 & 2.8 & 2.6 \\
\hline A10AE & Long-acting insulins & $<0.1$ & $<0.1$ & $<0.1$ & 0.5 & 1.1 & 1.8 & 2.6 & 3.3 & 4.1 & 4.8 & 5.3 & 5.9 & 6.4 \\
\hline$A 10 B$ & Non-insulin antidiabetics & & & & & & & & & & & & & \\
\hline A10BA & Biguanides & 12.8 & 13.5 & 14.9 & 17.4 & 18.0 & 17.7 & 18.0 & 19.2 & 20.9 & 22.1 & 22.6 & 23.0 & 23.1 \\
\hline $\mathrm{A} 10 \mathrm{BB}$ & Sulphonylureas & 24.9 & 23.7 & 23.2 & 22.3 & 21.0 & 19.7 & 18.5 & 18.8 & 19.2 & 18.8 & 17.8 & 16.7 & 15.8 \\
\hline A10AF & a-glucosidase inhibitors & 3.4 & 3.3 & 3.2 & 3.0 & 2.7 & 2.4 & 2.1 & 1.9 & 1.7 & 1.5 & 1.2 & 1.0 & 0.8 \\
\hline $\mathrm{A} 10 \mathrm{BG}$ & Glitazones & 0.2 & 0.2 & 0.6 & 1.0 & 1.0 & 1.1 & 1.1 & 1.0 & 0.9 & 0.8 & 0.6 & 0.5 & 0.5 \\
\hline $\mathrm{A} 10 \mathrm{BH}$ & DPP-4 inhibitors & - & - & $>0.1$ & 2.4 & 3.6 & 3.8 & 4.1 & 4.4 & 4.9 & 5.6 & 6.1 & 6.5 & 6.8 \\
\hline$A 10 B J$ & GLP-1 analogues & - & - & - & - & - & - & - & - & - & 0.3 & 0.8 & 1.0 & 1.2 \\
\hline A10BK & SGLT2 inhibitors & - & - & - & - & - & - & - & - & - & $<0.1$ & 1.0 & 2.0 & 3.0 \\
\hline $\mathrm{A} 10 \mathrm{BX}$ & Other non-insulin antidiabetics & 0.3 & 0.5 & 0.6 & 0.6 & 0.6 & 0.5 & 0.5 & 0.4 & 0.4 & 0.3 & 0.3 & 0.2 & 0.2 \\
\hline $\mathrm{A} 10 \mathrm{BD}$ & Oral fixed-dose combinations & 2.4 & 4.1 & 5.1 & 5.3 & 8.5 & 12.4 & 15.0 & 16.0 & 17.9 & 18.9 & 19.5 & 20.3 & 21.4 \\
\hline
\end{tabular}

Note: The results presented in Table 1 were rounded to the first decimal place. The authors performed all calculations with raw data. Therefore, calculating annual growth rates with Table 1 data may lead to slightly different results than those presented in the text of this article 
Ultimately, insulins and their analogs represented $17.4 \%$ of the total consumption of antidiabetic drugs.

The consumption of noninsulin antidiabetic drugs was 44.0 DDD/TID in 2005 and increased to 72.9 DDD/TID in 2017. The increase in consumption slowed between 2014 and 2017, with an annual average growth rate of $2.2 \%$. If noninsulin antidiabetic drugs represented $89.2 \%$ of the total antidiabetic drugs consumed in 2005, their representativity decreased to $82.6 \%$ in 2017.

\section{Insulins and their analogs (ATC fourth level)}

Between 2014 and 2017, the consumption of long-acting insulins exhibited an annual average increase of $11.7 \%$. Furthermore, fast-acting insulins, despite the less marked variation, followed the trend of long-acting insulins. In 2017, these two types of insulin represented $70.1 \%$ of the total insulin consumed.

In 2014, the combined-acting insulins represented of $22.1 \%$ of the total insulin consumption. However, in 2017, this percentage decreased to $16.9 \%$. The intermediate-acting insulins, which were the most frequently consumed type of insulin in 2005, with a representativity of $56.7 \%$ of all insulins, displayed a decrease in consumption that was accompanied by an increase in the consumption of other insulins and displayed a relative consumption of $13.0 \%$ in 2017.

\section{Noninsulin antidiabetic drugs (ATC fourth level)}

From 2005 to 2017, the consumption of biguanides increased from 12.8 to $23.1 \mathrm{DDD} / \mathrm{TID}$, achieving first place in this group of noninsulin drugs. From 2014 to 2017, the consumption of sulphonylureas decreased annually, on average by $5.3 \%$. In 2017 , the value remained at 15.8 DDD/TID. In 2017, the consumption of DPP-4 inhibitors reached 6.8 DDD/TID, representing an annual average growth rate of $7.3 \%$ between 2014 and 2017 .

In 2017, $\alpha$-glucosidase inhibitors, glitazones, and a group of other noninsulin antidiabetic drugs (nateglinide) were consumed at lower levels in descending order.

In 2017, the consumption of new medicine classes, glucagon-like peptide-1 (GLP-1) analogs and sodiumglucose cotransporter 2 (SGLT2) inhibitors, reached 1.2 and 3.0 DDD/TID, respectively.

\section{Oral fixed-dose combinations}

Oral fixed-dose combinations experienced an annual average growth rate of $78.0 \%$ between 2005 and 2014 and $4.5 \%$ between 2014 and 2017. In 2017, these combinations achieved an impressive consumption level of 21.4 DDD/TID, which represents $29.4 \%$ of noninsulin antidiabetic drugs (Fig. 2).

In 2005, oral fixed-dose combinations were practically represented by metformin combined with sulphonylurea, with a representativity of $95.2 \%$. However, with the decrease in the absolute level of consumption of this combination and the emergence and increased consumption of metformin combined with a DPP-4 inhibitor, the first combination represented $2.1 \%$ and the second combination represented $92.6 \%$ of the consumption of this drug class in 2017.

Notably, in 2017, the consumption of metformin and DPP-4 inhibitors reached 23.1 and 6.8 DDD/TID, respectively. However, in the same year, the consumption of metformin in combination with a DPP-4 inhibitor was 19.8 DDD/TID.

Among the new class of medicines, the consumption of metformin in combination with an SGLT2 inhibitor was 0.8 DDD/TID in 2017. This value achieved second place in the consumption of oral-fixed dose combinations.

\section{District-level variations}

In 2017, the districts with the highest levels of consumption of antidiabetic drugs were Bragança (109.9 DDD/ TID) and Vila Real (107.8 DDD/TID), and the districts with the lowest levels of consumption were Faro (69.1 DDD/TID) and Lisbon (76.4 DDD/TID). From 2014 to 2017, the greatest increase in consumption occurred in the Bragança district, with an annual average increase of $4.2 \%$, and the lowest consumption was observed in Beja, with an annual average decrease of $1.8 \%$ (Fig. 3: map A).

In 2017, the districts with the highest levels of consumption of insulins and their analogs were Coimbra (21.6 DDD/TID) and Castelo Branco (21.1 DDD/TID), and the districts with the lowest levels of consumption were Lisbon (13.1 DDD/TID) and Braga (13.3 DDD/ TID). From 2014 to 2017, the greatest increase in consumption occurred in the Évora district, with an annual average increase of $4.8 \%$, and the lowest consumption occurred in Coimbra, with an annual average increase of $1.4 \%$ (Fig. 3: map B).

In 2017, the districts with the highest levels of consumption of noninsulin antidiabetic drugs were Vila Real (92.7 DDD/TID) and Bragança (90.8 DDD/TID), and the districts with the lowest levels of consumption were Faro (55.7 DDD/TID) and Lisbon (63.3 DDD/TID). From 2014 to 2017, the greatest increase in consumption occurred in the Bragança and Viana do Castelo districts, both with an annual average increase in consumption of $3.7 \%$, and the lowest consumption was observed in Beja, with an annual average increase of $0.7 \%$ (Fig. 3: map C).

\section{Northern/southern and coastal/inland district comparisons}

The average consumption of antidiabetic drugs in the northern districts was 52.6, 89.3, and 96.9 DDD/TID in 2005,2014 , and 2017, respectively, and the values in the southern districts were 52.7, 86.9, and 90.2 DDD/TID in 2005, 2014, and 2017, respectively. 


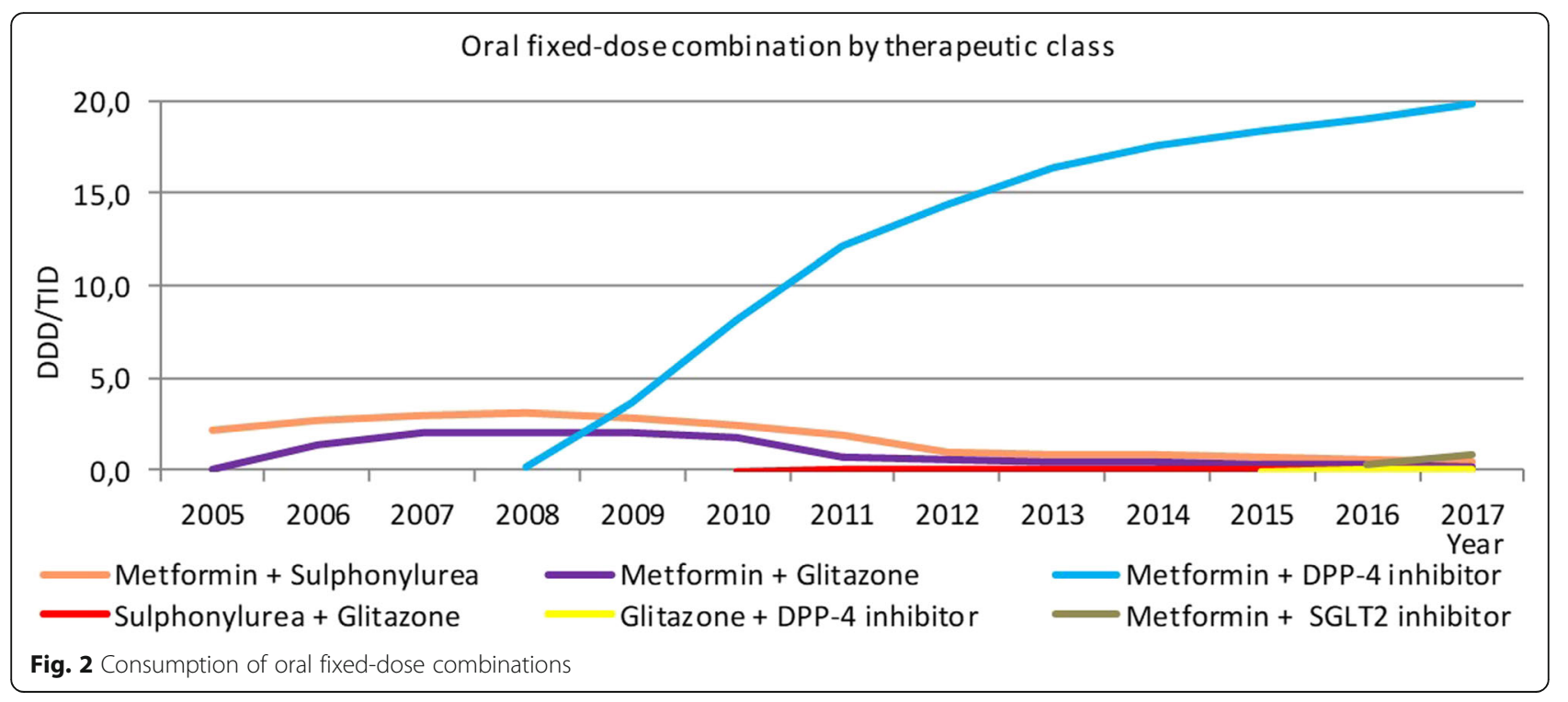

The average consumption of insulins and their analogs in the northern districts was 6.2, 15.8, and 17.3 DDD/ TID in 2005, 2014, and 2017, respectively, and 5.3, 13.5, and 15.1 DDD/TID in the southern districts in 2005, 2014, and 2017, respectively.

The average consumption of noninsulin antidiabetic drugs in the northern districts was 46.4, 73.4, and 79.6 DDD/TID in 2005, 2014, and 2017, respectively, and 47.5, 71.4, and 75.2 DDD/TID in the southern districts in 2005,2014 , and 2017, respectively.

In the division between northern and southern districts, the difference between the average levels of consumption of antidiabetic drugs, insulins and their analogs, or noninsulin antidiabetics never achieved statistical significance in any year, except for insulins and their analogs in 2014 (Mann-Whitney U test: $\mathrm{p}=0.020$ ).

The average consumption of antidiabetic drugs in the coastal districts was 49.0, 80.6, and 87.3 DDD/TID in 2005, 2014, and 2017, respectively, and 56.3, 96.2, and 101.3 DDD/TID in the inland districts in 2005, 2014, and 2017, respectively. In each year analyzed, the average consumption of antidiabetic drugs in the coastal districts was always lower than that of the inland districts, indicating that these differences were statistically significant (Mann-Whitney U test: $p=0.019, p<0.001, p=0.001$, respectively, for each year).

The average consumption of insulins and their analogs in the coastal districts was 5.5, 14.3, and 15.7 DDD/TID in 2005, 2014, and 2017, respectively, and 6.2, 15.5, and 17.1 DDD/TID in the inland districts in 2005, 2014 and 2017 , respectively. In each year of observation, the average consumption of insulins and their analogs in the coastal districts was always lower than that in the inland districts. However, none of these differences were statistically significant.

The average consumption of noninsulin antidiabetic drugs in the coastal districts was 43.5, 66.7, and 71.6 DDD/TID in 2005, 2014, and 2017, respectively, and 50.1, 78.5, and 84.2 DDD/TID in the inland districts in 2005, 2014, and 2017, respectively. In each year analyzed, the average consumption of noninsulin antidiabetics in the coastal districts was always lower that in the inland districts, and these differences were statistically significant (Mann-Whitney $\mathrm{U}$ test: $p=0.014, p=$ $0.001, p=0.003$, respectively, for each year).

\section{Discussion}

The data enable a multifaceted discussion, regardless of whether the results were obtained per se or whether they were attributed to any relationship with diabetes.

The analysis of the period between 2005 and 2017, representing 13 years of data, provides information on the overall trends and evolution of consumption for a reasonable period. However, due to the availability of new antidiabetic drugs and their inclusion in two guidelines published in 2013 and 2015 [15, 16], the period between 2014 and 2017 was highlighted in the results and the discussion.

In the period analyzed, 2005 to 2017 , the consumption of antidiabetic drugs, insulins and their analogs, and noninsulin antidiabetic drugs was characterized by consistent growth, as shown in other studies [24, 25]. Notably, the proportion of consumption of insulins to noninsulin drugs also increased. The growth in the consumption of these medicines may be explained by an increasing number of people diagnosed with type 2 


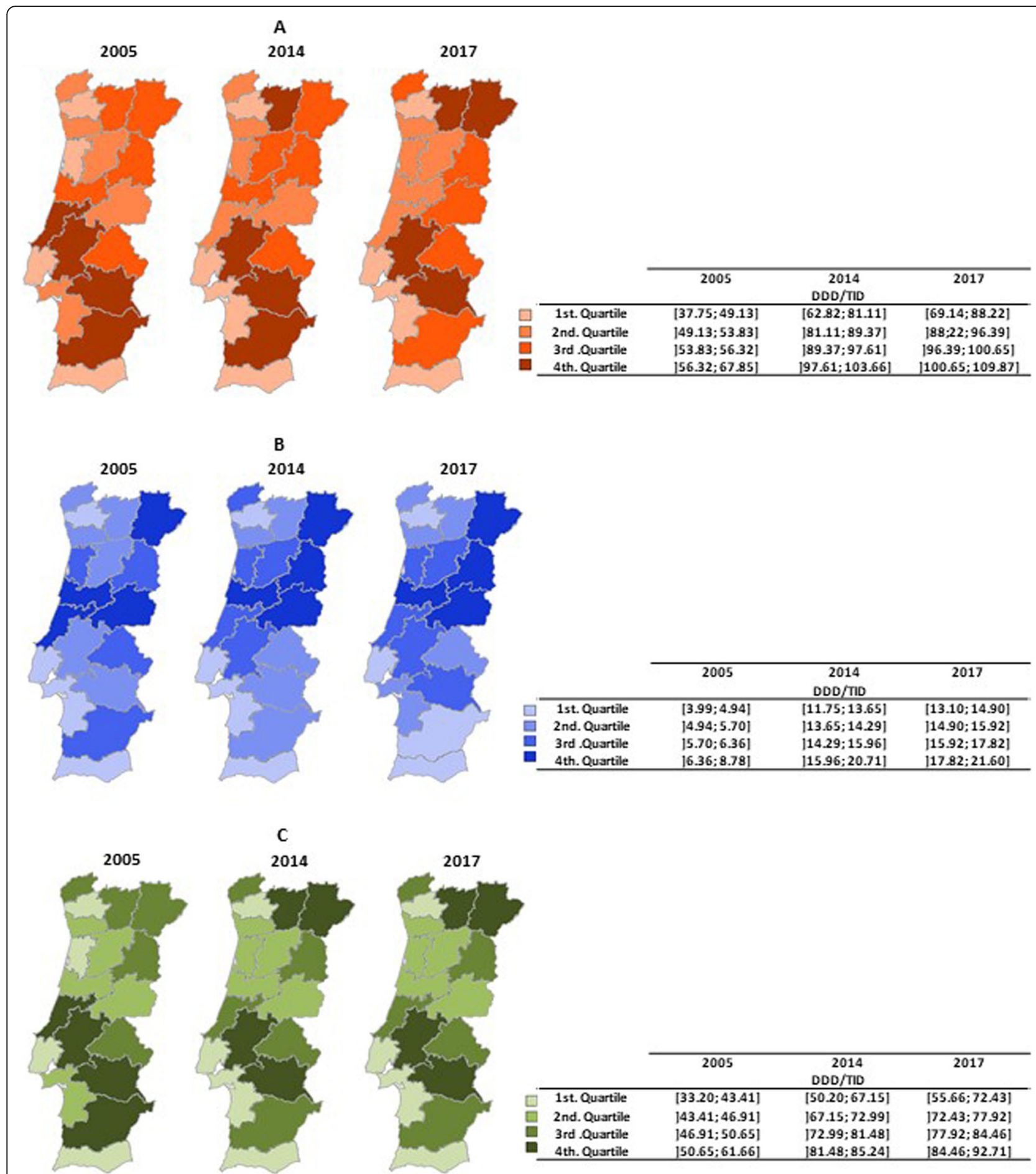

Fig. 3 Consumption of drugs - a antidiabetics, $\mathbf{b}$ insulins and their analogs, and $\mathbf{c}$ noninsulin antidiabetics

diabetes mellitus and by the fact that nonglycemiccontrolled type 2 diabetes mellitus patients started being treated with an increasing number of noninsulin antidiabetic drugs or even accepting the use of insulin.

Consulting the OECD statistics for the total consumption of antidiabetic drugs reported in DDD/TID [26], per county, which includes data from 28 countries in 2017, Portugal is in 14th place in descending order (68.1 DDD/TID) between Belgium (71.0 DDD/TID) and South Korea (66.9 DDD/TID). Based on the results obtained from the present study (88.2 DDD/TID), Portugal would be the second country after Finland (92.1 DDD/TID) in 
terms of consumption. The likely explanation for the difference between the findings of this study and the OECD statistics is that the national authority database does not include the consumption of oral fixed-dose combination drugs in DDD, as explained in the methods section.

The consumption of insulins and their analogs increased substantially. From 2005 to 2014, their consumption increased at a high rate, and their consumption increased at a lower rate from 2014 to 2017. The sharp increase in the consumption of long-acting and, to a lesser extent, fastacting insulins is very significant. In 2017, the situation was very different from the value of approximately 6 DDD/TID observed in 2000 [27]. The same trend has been observed in Denmark, where an increase in the number of users of insulins and their analogs, including fastacting insulins, was observed from 1999 to 2014, and a substantial increase in the number of users of long-acting insulins was observed from 2004 to 2014 [20]. The same trend was observed in the Granada region of Spain in a study examining data collected from 2001 to 2014 [21].

At the end of the period analyzed here, the consumption of metformin exceeded the consumption of sulphonylureas, without considering the combination with a DPP-4 inhibitor. From a different perspective, a study performed in France revealed the same trend [28]. In 2006, $58 \%$ of the patients initiating type 2 diabetes mellitus treatment with noninsulin antidiabetic drugs started with metformin as the first-line treatment, while $34 \%$ initiated treatment with sulphonylureas. This difference increased significantly at the end of the study in 2013; $80 \%$ started with metformin and $15 \%$ were first with sulphonylureas.

The increase in the use of insulins and metformin is consistent with the clinical guidelines [14-19]. Of course, with some delay, these successive guidelines exerted a positive effect on the consumption of insulins and metformin over time. For example, a consistent decrease in sulphonylurea consumption and a consistent increase in metformin consumption were observed throughout the period studied, as metformin consumption only exceeded sulphonylurea consumption in 2012.

Surprisingly, the relative consumption of the fixeddose combination of metformin with a DPP-4 inhibitor was higher than that of DPP-4 inhibitors alone. A relevant reference to the substantial consumption of DPP4 inhibitors is the study by C. Torre et al. [29]. This study compares consumption in Portugal and the Netherlands based on data from 2013. In the Netherlands, DPP-4 inhibitors are less than $5 \%$ of the total noninsulin antidiabetic drugs consumed, and fixeddose combinations are consumed at residual levels. Based on our study, for the same year, the consumption of the fixed-dose combination of metformin with a DPP-
4 inhibitor was 16.3 DDD/TID (corresponding to $24.8 \%$ of noninsulin antidiabetic drugs), while DDP-4 inhibitor consumption was $4.9 \mathrm{DDD} / \mathrm{TID}$ (corresponding to $7.3 \%$ of noninsulin antidiabetic drugs). Compared with the Netherlands, we concluded that Portugal exhibited substantial consumption of these drugs. Notably, the OECD reports an age-standardized diabetes prevalence of $4.6 \%$ for the population aged 18-99 years in the Netherlands and $9.9 \%$ in Portugal based on data collected in 2017 [10]. However, this last aspect does not explain the difference in consumption of this class of drug and its combination with metformin between the two countries. Most likely, these findings are related to differences in the clinical practice between Portugal and the Netherlands.

Returning to the topic of the consumption of a fixeddose combination of metformin with a DPP-4 inhibitor and the high values observed in Portugal, the consumption of these drugs increased to $25.7 \%$ in 2014 in relation to the total consumption of noninsulin antidiabetic drugs. In the same year, the value was $12.2 \%$ for the Granada region [21]. Therefore, compared to this last study, these fixed-dose combination drugs are consumed at very high levels in Portugal.

Based on the data collected in the last few years, the consumption of the new medicine classes of GLP-1 analogs and SGLT2 inhibitors is expected to increase in the next few years.

The estimated prevalence of diabetes in 2015 was $13.3 \%$, and the estimated prevalence of diagnosed diabetes was $7.5 \%$ [11]. Using the diagnosed population, an average daily consumption by individuals with diabetes of 1.12 DDD was obtained. We believe that this parameter is interesting, and a comparison of the consumption in different countries or regions would be useful, as this analysis would consider the population with diabetes instead of the total population.

Regarding the consumption of antidiabetic drugs, insulins and their analogs, or noninsulin drugs, at the district level, looking at the distribution per quartile, there were many changes in the positions on the years analyzed (2005, 2014, and 2017). In this way, it is interesting to observe, for each district, the dynamics for long-term (2005 versus 2014 and 2005 versus 2017) and mediumterm (2014 versus 2017) relative changes in the consumption of these medicines.

Previous studies have observed differences in the consumption of antidiabetic drugs in different regions of Portugal $[24,25]$. In Italy, substantial differences in the consumption of antidiabetic drugs were also observed at the regional level; higher levels of consumption were observed in the south that in the north [30].

When comparing the consumption of antidiabetic drugs and noninsulin drugs between north and south 
districts, the differences were not statistically significant. Concerning insulins and their analogs, although consumption in the northern districts was always higher than that in the southern districts, the results were statistically significant for only 2014. It is difficult to explain the reason for this last result, but it is probably related to several different factors.

Concerning the comparison of the consumption of insulins and their analogs between coastal and inland districts, there were no statistically significant differences in any of the years analyzed, but the average consumption was always higher in the inland districts. For the consumption of antidiabetic drugs and noninsulin drugs, the consumption was always higher in the inland districts, and these differences were statistically significant for all years under analysis (2005, 2014, and 2017). Inland districts have a larger elderly population, which probably explains the results obtained.

The concept of consumption in the market is not completely consistent with the concept of taking the drug. This study enabled us to characterize the levels of exposure of a population to a drug or groups of drugs, as well as their long-term fluctuations, and establish comparisons between these exposure levels in populations from different geographical areas. Nevertheless, we reasonably concluded that antidiabetic drugs are essentially consumed by people with diabetes, as other therapeutic indications and off-label uses are very rare. In this study, the limitations principally arise from the source of information. The data do not allow us to analyze the relationship between market consumption and the variables of the patient (its characterization, including $\mathrm{HbA} 1 \mathrm{c}$ levels, years of diagnosed diabetes mellitus type 2, diabetes complications, etc.) or of the prescriber (prescriber characteristics such as age, medical specialty, type of medical institution, etc.).

The monetary values of the total outpatient drug market of $78.1 \%$ in 2014 and $74.9 \%$ in 2017 corresponded to the Health Service outpatient drug market [31]. However, all antidiabetic medicines are reimbursed by health services. Therefore, an important aspect to consider regarding the origin of the database is that the market value for insulin and noninsulin antidiabetic drugs reported in 2011 by the outpatient Health Service in relation to the total outpatient market value of these same drugs corresponded to $96.5 \%$ [32]. This value reflects an approximately global representativity of the antidiabetic drugs in the outpatient market.

\section{Conclusions}

The main results reveal a consistent increase in the consumption of antidiabetic drugs, insulins and their analogs, noninsulin drugs, long-acting and fast-acting insulins, metformin, DPP-4 inhibitors, and fixed-dose combinations of metformin with a DPP-4 inhibitor.

At the end of the period examined in the present study, the new classes of antidiabetic medicines, particularly SGLT2 inhibitors, achieved a representative consumption level.

In mainland Portugal, the regional differences in the consumption of antidiabetic drugs or their subtypes are marked by a geographical division between the coastal and inland districts rather than by a geographical division between the northern and southern districts. In this regional comparison, the consumption of several different drugs reached statistical significance.

The main contribution of this article is that it provides insights for future research analyzing the effects of changes in the consumption of antidiabetics on the treatment of the population with diabetes.

\section{Abbreviations}

ACSS: Health Service's Central Management; ATC: Anatomical Therapeutic Chemical Classification System; DDD: Defined daily dose; DGS: Portuguese General Directorate of Health; DPP-4: Dipeptidyl peptidase-4; GLP-

1: Glucagon-like peptide-1; Infarmed: Portuguese Medicines Authority; OECD: Organisation for Economic Cooperation and Development; OND: Portuguese National Diabetes Observatory; SGLT2: Sodium-glucose cotransporter 2; SPD: Portuguese Society of Diabetology;

TID: 1000 inhabitants per day; WHO: World Health Organization

\section{Acknowledgements}

The authors wish to express our thanks to Infarmed for providing the data used in this study. The authors would also like to thank Silvia Franco (Pharm D) for the English language review.

\section{Authors' contributions}

The research was conceptualized and designed by all authors in collaboration. AMM played a main role in drafting and revising. SOM and JFR contributed to supervision in drafting and revising. All authors have approved the submitted version of the manuscript.

\section{Funding}

There was no funding for this study.

\section{Availability of data and materials}

All data are available at Infarmed, upon request.

\section{Ethics approval and consent to participate}

According to current Portuguese law (DL 21/2014 and DL 80/2018) this study does not require a review by an Ethics Committee, as the database received did not contain any subject-related data. The information available in the database only contained aggregate quantification of consumption for each drug (ATC 5th level) per district and year. The concept of consent to participate is not applicable.

Infarmed (Portuguese Medicines Authority) provided the database for the study and authorized its use. No additional authorizations to use this data are required under Portuguese law.

\section{Consent for publication}

Not applicable.

\section{Competing interests}

The authors have no competing interests to declare.

\section{Author details}

${ }^{1}$ Faculty of Pharmacy, University of Lisbon, Avenida Professor Gama Pinto, 1649-003 Lisboa, Portugal. ${ }^{2}$ Nova Medical School, New University of Lisbon, 
Lisboa, Portugal. ${ }^{3}$ Portugal and Portuguese Diabetes Association (APDP), Lisboa, Portugal.

Received: 26 March 2020 Accepted: 3 February 2021

Published online: 24 February 2021

\section{References}

1. WHO Expert Committee. The Selection of Essential Drugs. Technical Report Series 615. Geneva: World Health Organization; 1977. https:/apps.who.int/ iris/bitstream/handle/10665/41272/WHO_TRS_615.pdf.

2. WHO, WHO-IWGDSM, WHO-CCDURCPS. Introduction to Drug Utilization Research. Oslo: World Health Organization; 2003. https://apps.who.int/iris/ bitstream/handle/10665/42627/924156234X.pdf.

3. Bergman U. Pharmacoepidemiology - from description to quality assessment: A Swedish perspective. Nor J Epidemiol. 2001;11(1):31-6. doi: https://doi.org/10.5324/nje.v11i1.531.

4. Luna FA. Farmacoepidemiología. Estudios de Utilización de Medicamentos Parte I: Concepto y metodología. Seguim Farm. 2004;2(3):129-36. http:// www.cipf-es.org/sft/vol-02/129-136.pdf.

5. Luna FA. Farmacoepidemiología. Estudios de Utilización de Medicamentos. Parte 2: Revisión de trabajos publicados en España. Seguim Farm. 2004;2(3): 209-16. http://www.cipf-es.org/stt/vol-02/209-216.pdf.

6. Gama H. Drug Utilization Studies. Arq Med. 2008;22(2/3):69-74. http://www. scielo.mec.pt/pdf/am/v22n2-3/22n2-3a06.pdf.

7. Truter I. A Review of Drug Utilization Studies and Methodologies. Jordan J Pharm Sci. 2008:1 (2):91-104. http://citeseerx.ist.psu.edu/viewdoc/downloa $\mathrm{d}$ ?doi=10.1.1.1006. $.1271 \& \mathrm{rep}=\mathrm{rep} 1 \&$ type $=$ pdf.

8. Sachdeva PD, Patel B. Drug Utilization Studies - Scope and Future Prerspectives. Int J Pharm Biol Res. 2010;1(1):11-7. https://pdfs.sema nticscholar.org/4dd2/96c69dc99a8ab717aec03eedd17291d16e3d.pdf.

9. Shalini S, Ravichandran V, Mohanty B, Dhanaraj S, Saraswathi R. Drug Utilization Studies - An Overview. Int J Pharm Sci Nanotechnol. 2010;3(1): 803-10. http://ijpsnonline.com/Issues/803_full.pdf.

10. OECD. Health at a Glance: Europe 2018. OECD Publishing; 2018. http://www. oecd-ilibrary.org/deliver/health_glance_eur-2018-en.pdf?itemld=/content/ publication/health_glance_eur-2018-en\&mimeType=application/pdf.

11. Observatório Nacional da Diabetes. Diabetes: Factos E Números - O Ano 2015. Sociedade Portuguesa de Diabetologia; 2016. http://spd.pt/images/ OND/DFN2015.pdf.

12. American Diabetes Association. Classification and diagnosis of diabetes: standards of medical care in diabetes - 2020. Diabetes Care. 2020; 43(January):14-31. doi:https://doi.org/10.2337/dc20-5002.

13. Direcção-Geral da Saúde. Crianças E Jovens Com Diabetes Mellitus Tipo 1 Manual de Formação Para Apoio Aos Profissionais de Saúde E de Educação: 2019. Lisboa: Direcção-Geral da Saúde; 2019.

14. Duarte R, Rodrigues ER, Duarte JS, Duarte A, Ruas MMA. Recomendações da Sociedade Portuguesa de Diabetologia para o tratamento da hiperglicemia e factores de risco na diabetes tipo 2. Rev Port Diabetes. 2007;2(4 Suppl):5-18. http://www.revportdiabetes.com/wp-content/uploads/2017/10/RPD-Vol-2no-4-Dezembro-2007-Suplemento-Recomendações-da-SPD-págs-5-18.pdf.

15. Duarte R, Nunes JS, Dores J, Medina JL. Recomendações nacionais da SPD para o tratamento da hiperglicemia da diabetes tipo 2 (com base na posição conjunta ADA/EASD). Rev Port Diabetes. 2013;8(1):4-29. http:// www.revportdiabetes.com/wp-content/uploads/2017/10/RPD-Vol-8-no-1-Ma rço-2013-Recomendações-págs-4-29.pdf.

16. Duarte $R$, Melo M, Nunes JS. Recomendações da International nacionais da SPD para o tratamento da hiperglicemia na diabetes tipo 2 - Proposta de actualização (adaptação do recente "update" 2015 da declaração de posição conjunta ADA/EASD). Rev Port Diabetes. 2015;10(1):40-8. http://www. revportdiabetes.com/wp-content/uploads/2017/11/RPD-Vol-10-no-1-Março-2 015-Recomendações-págs-40-48.pdf.

17. Norma da DGS n. 52/2011 - actualizada a 27/4/2015. Abordagem Terapêutica Farmacológica Na Diabetes Mellitus Tipo 2 No Adulto. Direcção-Geral da Saúde; 2015. https://www.dgs.pt/directrizes-da-dgs/normas-e-circularesnormativas/norma-n-0522011-de-27122011-atualizada-a-30072013-jpg.aspx.

18. Norma da DGS n. 1/2011 - de 7/1. Terapêutica Da Diabetes Mellitus Tipo 2: Metformina. Direcção-Geral da Saúde; 2011. https://www.dgs.pt/programanacional-para-a-diabetes/circulares-normas-e-orientacoes/norma-da-direcca o-geral-da-saude-n-0012011-de-07012011-pdf1.aspx.

19. Norma da DGS n. 25/2011 - actualizada a 27/1/2014. Insulinoterapia Na Diabetes Mellitus Tipo 2. Direcção-Geral da Saúde; 2014. https://www.dgs.pt/ directrizes-da-dgs/normas-e-circulares-normativas/norma-n-0252011-de-2 9092011-atualizada-a-30072013-jpg.aspx.

20. Christensen DH, Rungby J, Thomsen RW. Nationwide trends in glucoselowering drug use, Denmark, 1999-2014. Clin Epidemiol. 2016;8:381-7. https://doi.org/10.2147/CLEP.S113211.

21. López-Sepúlveda R, Lirola MÁG, García EE, et al. Antidiabetic medications use trends in an Andalusian region from 2001 to 2014. Prymary Care Diabetes. 2017;11:254-64. doi:https://doi.org/10.1016/j.pcd.2017.01.003.

22. WHO Collaborating Centre for Drug Statistics Methodology. Guidelines for ATC Classification and DDD Assignment 2018. Oslo; 2017. https://www.drugsa ndalcohol.ie/29364/1/WHO Collaborating Centre for Drug Statistics Methodology.pdf.

23. Instituto Nacional de Estatística. Data base of the annual average of the population by district and year. (2005-17). www.ine.pt. Accessed February $13,2019$.

24. Carmona MFDR. Caracterização (Farmaco)epidemiológica Da Diabetes Tipo 2 Em Portugal. Lisboa: Departamento de Sócio-Farmácia da Faculdade de Farmácia da Universidade de Lisboa; 2011. https://repositorio.ul.pt/bitstrea m/10451/5869/1/ulsd062274_td_Maria_Carmona.pdf.

25. OPSS. Relatório Primavera 2018. http://opss.pt/wp-content/uploads/2018/06/ relatorio-primavera-2018.pdf.

26. OECD.Stat. Database of consumption of antidiabetic drugs (ATC A10), in DHD and by year, for several countries. http://stats.oecd.org/. Accessed February 4, 2020.

27. Melander A, Folino-Gallo P, Walley T, et al. Utilisation of antihyperglycaemic drugs in ten European countries: different developments and different levels. Diabetologia. 2006;49:2024-9. doi:https://doi.org/10.1007/s00125-0060331-3.

28. Arnaud M, Bezin J, Bégaud B, Pariente A, Salvo F. Trends in the incidence of use of noninsulin glucose-lowering drugs between 2006 and 2013 in France. Fundam Clin Pharmacol. 2017;(31):663-75. doi:https://doi.org/1 $0.1111 / f c p .12298$.

29. Torre C, Guerreiro J, Martins S, de O, Raposo JF, Martins AP, Leufkens H. Patterns of glucose lowering drugs utilization in Portugal and in the Netherlands. Trends over time. Prim Care Diabetes April 2015:1-8. doi:https:// doi.org/10.1016/j.pcd.2015.03.009.

30. Osservatorio Nazionale sull'impiego dei Medicinali. L'uso Dei Farmaci in Italia. Rapporto Nazionale 2017. Roma: Agenzia Italiana del Farmaco; 2018. http://www.aifa.gov.it/sites/default/files/Rapporto_OsMed_2017_AlFA.pdf.

31. Direcção de Informação e Planeamento Estratégico. Estatística Do Medicamento E Produtos de Saúde 2017. Infarmed; 2018. http://www.infa rmed.pt/documents/15786/1229727/Estatística+do+Medicamento+2017/ c759b946-9dcb-4b0a-b10b-6287bf76c1 14? ?version=1.0.

32. Observatório Nacional da Diabetes. Diabetes: Factos E Números 2012 Relatório Anual Do Observatório Nacional de Diabetes. Lisboa: Sociedade Portuguesa de Diabetologia; 2013. https:/www.spd.pt/images/ond2013.pdf.

\section{Publisher's Note}

Springer Nature remains neutral with regard to jurisdictional claims in published maps and institutional affiliations.

Ready to submit your research? Choose BMC and benefit from:

- fast, convenient online submission

- thorough peer review by experienced researchers in your field

- rapid publication on acceptance

- support for research data, including large and complex data types

- gold Open Access which fosters wider collaboration and increased citations

- maximum visibility for your research: over $100 \mathrm{M}$ website views per year

At $\mathrm{BMC}$, research is always in progress.

Learn more biomedcentral.com/submissions 